\title{
Selection of Suitable Supervised Classification Techniques for the Geographic Analysis of Land Using GIS Techniques
}

\author{
S.L. Senthil Lekha ${ }^{1 *}$, S.S. Kumar ${ }^{2}$ \\ ${ }^{I}$ Department of Electronics and Communication Engineering, Noorul Islam Centre for Higher Education, Kumarakoil, Tamilnadu, \\ India. \\ ${ }^{2}$ Department of Electronics and Instrumentation Engineering, Noorul Islam Centre for Higher Education, Kumarakoil, Tamilnadu, \\ India.E-mail:kumar_s_s@hotmail.com \\ *Corresponding author E-mail:lekhasuresh20@gmail.com
}

\begin{abstract}
Nation has realised the changes in the land surface and the influence of this in the whole ecosystem. The activities of human on land is directly deteriorating the environment quality. This paper mainly focuses on the analysis of the destruction of land cover with the development of land use. The performance of five different Supervised Classification algorithms, which are Parallelepiped, Mahalanobis, Neurel Net, Adaptive Coherence and Spectral Angle Mapper have been analysed in classifying the Landsat Image of kanyakumari district. Automatic classification of five classes using training data have been performed and the best suitable algorithm for the classification of each class have been analysed. Being a tourism centre with coastal areas on all three sides, the development and the deterioration of kanyakumari district have to be monitored constantly. The proposed system is an automatic approach which helps in the analysis of the patterns of land use and land cover which constantly changes and to map each class clearly and distinct from each other using GIS techniques. The system was evaluated using the performance measures like accuracy and kappa coefficient using the tools Envi, ArcGIS and QGIS. From the performance analysis, the Spectral Angle Mapper with an overall accuracy of 97\% and kappa coefficient of 0.54 has been selected as the best suitable algorithm for the classification of landsat image of kanyakumari district.
\end{abstract}

Keywords: Kanyakumari, landsat image, Envi 5.1, QGIS.

\section{Introduction}

The changes that affect the nature can be well understood by the analysis of Land Use/Land Cover (LULC) (Dickinson, 1995; Gupta and Srivastava, 2010; Mukherjee et al., 2007; Patel et al., 2012; Srivastava et al., 2011). Biophysical, social and economic factors are playing a major part in the remarkable change in land cover (Aspinall, 2004; Zeng et al., 2008). The term "land cover" and "land use" which sometimes leads to confusion is represented using different colours and it concludes that the land cover can be taken as what covers the earth naturally and land use is the usage of land by human beings. The land cover classes that are considered in this analysis are water, forest area, bare soil and hilly Areas. Land used by human include built-up and agricultural land.

The major rule in environmental development is acquired by the LULC classification and analysis (Iqbal and Khan, 2014; Kantakumar and Neelamsetti, 2015; Lin et al., 2015). Spectral property plays the main role in classification to achieve the accurate output of Landsat images (USGS, 2004; Muttitanon and Tripathi, 2005; Kawakubo et al., 2011). satellite images are used as the main source to study the environment in detail and to obtain good knowledge. (Misra et al., 2013). The mapping of Land use land cover features using available maps, records and field survey data (conventional method) is often time consuming, exhaustive and expensive and cannot be updated to meet up with the rapidly changing environment (Anderson et al., 1976; Singh, 1989;
Nemani and Running, 1997; Nayak, 2002; Wang et al., 2004, Rawat et al., 2013). GIS and remote sensing techniques provides the better accuracy and decision making in the scientific field. The main objective of this study focuses on the comparison of five different classification algorithms to select the best suitable method for the classification of each class of Landsat image of KanyaKumari district. The five algorithms are Parallelepiped Classification, Mahalanobis Distance Classification, Neural Net (NN) Classification, Adaptive Coherence Estimation and Spectral Angle mapper in which Spectral Angle Mapper outperformed all other classifiers.

\section{Study Area and Data}

Kanyakumari district, the study area chosen for analysis is a land of remarkable diversity, ignites and excites every tourist's curiosity by the beauty of majestic hills, plains, idyllic beaches and colourful sea-shores. Fringed with lush paddy fields, coconut plantations, undulating valleys and plains between the mountainous terrain, villages interwoven with factories, temples, mosques, commercials and other establishments lies the district, 'Kanyakumari', With an area of 1672 sq.km, occupying $1.29 \%$ of the area of Tamil nadu and ranking first in literacy among other districts in Tamil nadu is the majestic area chosen for analysis.

The imagery for analysis could be in printed form, which can be classified using visual interpretation methods or in digital form, for which we need some software to view and process. Satellite images provide accurate geospatial information describing the 
transformation in LULC (Foody, 2003; Herold et al., 2002; Yuan et al., 2005). The study area chosen for analysis is Kanyakumari district which is the popular tourist place where three seas meet namely, Bay of Bengal, Indian ocean and Arabian sea. It is the southernmost district in the state of Tamil Nadu and is also the southernmost tip of Indian peninsula. Established in 1 November 1956, it has the headquarters as nagercoil, and it has four talukas Agastheeswaram, Kalkulam, Thovalai, and Vilavancode.

The image selected for analysis was recorded on 22-01-2015

(LANDSAT SCENE ID = LC81430542015022LGN00).

The landsat image with datum World Geodetic System WGS84 of 2015-Landsat_8 was taken for analysis. Datum, a model of the earth that is used in mapping consists of a series of numbers that defines the shape and size of the ellipsoil and its orientation in the space. It is chosen to give the best possible fit to the shape of the earth. An open access and free data is a key to our research which was obtained from the http://bhuvan.nrsc.gov.in online portal. The three primary information required for the geometric characterization and calibration operations are ground control points, reference images, and digital terrain data.

Landsat-8

Landsat- 8 is bound with 11 bands which measures the different ranges of frequencies along the electromagnetic spectrum. The main bands used for the analysis of kanyakumari district are green, red and INR sensors which are recognized as 3,4, and 5. Of 11 bands, one in the shortest wavelengths (bands $1-4$ and 8) sense visible light, all others are in parts of the invisible spectrum.

\begin{tabular}{|l|c|c|}
\hline Landsat 8 Bands & Wavelength(micrometers) & Resolution(meters) \\
\hline \hline Band 2-Blue & $0.450-0.515 \boldsymbol{\mu m}$ & $30 \mathrm{~m}$ \\
\hline Band 3-Green & $0.525-0.600 \mu \mathrm{m}$ & $30 \mathrm{~m}$ \\
\hline Band 4-Red & $0.630-0.680 \mu \mathrm{m}$ & $30 \mathrm{~m}$ \\
\hline $\begin{array}{l}\text { Band 5-Near } \\
\text { Infrared (INR) }\end{array}$ & $0.845-0.885 \mu \mathrm{m}$ & $30 \mathrm{~m}$ \\
\hline
\end{tabular}

\section{The Bands}

The bands chosen for the analysis of the Landsat- 8 image is based on the priority of the analysis. We have chosen the bands 2,3 , and 5 for our analysis and these are Band 2-visible blue, Band 3 green, and Band 5 measures the near infrared, as NIR which is especially important for the analysis of vegetation, as it is reflected by healthy plants. NDVI gives the plant health and greenness of the vegetation. Band 9 is used for the analysis of clouds and Bands 10 and 11 are in the thermal infrared (TIR).

Ground Control Points are points on the surface of the earth of more than three known location used to geo-reference Landsat data. The ground control point binary files can be extracted from the USGS EROS GCP library over our area of interest. In this analysis we have used four ground control points $(8.29,77.09)$, $(8.08,77.5),(8.14,77.5),(8.57,772.7)$ to georeference and digitize the base map. The sun elevation angle for the Landsat- 8 image of 22-01-2051 is given as

Sun Elevation: 50.09543261

Earth sun distance: 0.9841761

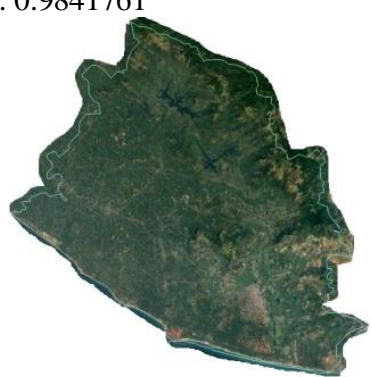

Fig. 1: Base map of kanyakumari RGB(4,3,2)

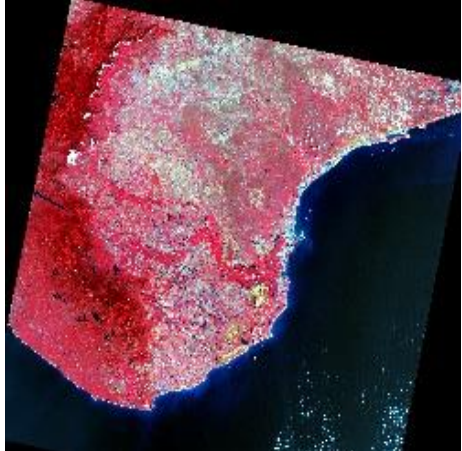

Fig. 2: Landsat -8 INR-RG $(5,4,3)$

\section{Methodology}

The flow of the experimental analysis is shown in Fig 3. The analysis was carried out in three main parts, Preprocessing, Classification and Postprocessing.

\subsection{Satellite Image Pre-Processing}

The Landsat- 8 image of kanyakumari district acquired from USGS EROS Center has quantized and calibrated scaled Digital Numbers (DN). The OLI and TIRS band data present in the image has to be converted to TOA spectral radiance using the scaling factors present in the metadatafile. It is a challenge for nonexperts to determine the exact amount of preproceesing needed for the analysis (Pettorelli et al. 2014).

The most popular spectral indices that is taken in to concern is the Normalized Difference Vegetation Index (NDVI), defined as (JARS, 1993).

$\mathrm{NDVI}=(\mathrm{NIR}-\mathrm{Red}) /(\mathrm{NIR}+\mathrm{Red}$

NIR - Near- Infrared

The values of NDVI range from -1 to 1 . Dense vegetative land gives a higher value, while low NDVI values show plain areas.

\section{Conversion to TOA radiance}

The Operational Land Imager (OLI) and Thermal Infrared Sensor (TIRS) are instruments onboard the Landsat- 8 satellite. OLI and TIRS band data can be converted to TOA spectral radiance using the scaling factors present in the metadata file.

$L_{\lambda}=M_{L} Q_{c a l}+A_{L}$

\section{Conversion to TOA reflectance}

USGS EROS captures L8 data and performs pre-processing before further process.

$\rho \lambda^{\prime}=M_{\rho} Q_{c a l}+A_{\rho}$

TOA reflectance with a correction for the sun angle is :

$\rho \lambda=\frac{\rho \lambda \prime}{\cos \left(\theta_{S Z}\right)}=\frac{\rho \lambda \prime}{\sin \theta_{S E}}$

\section{Conversion to top of atmosphere brightness temperature}

The Landsat- 8 system with high data quality is very robust. The thermal constants which was provided in the meta data file of L8 was used to convert the TIRS band data from spectral radiance to top of atmosphere brightness temperature.

$\mathrm{T}=\frac{\mathrm{K} 2}{\ln \left(\frac{\mathrm{k} 1}{\mathrm{~L}_{\lambda}}+1\right)}$ 


\section{Dark Object Subtraction}

Dark Object Subtraction is an empirical atmospheric correction method for satellite imagery to bring out the pixels that are hidden in complete shadow. Dark object subtraction finds the darkest pixel value in each band and the scattering is removed by subtracting this value from every pixel in the band. The darkest pixel value is found by a histogram, finding the point where the DN values rise dramatically and use that as the constant value to subtract from each band.

\subsection{Feature Extraction}

Features that are extracted from the images can be divided in to two, based on the application. They are local and global features. Global features are generally used in image retrieval, object detection and classification, while the local features are used for object identification. In this analysis the features extracted by creating the polygons are the global features. The latest Google Earth and the photo interpretation techniques were used to recognize and confirm the different features in the study area. The region of interest(ROI) and the spectral signatures are the major requirements for the feature extraction. Confusion among the features can be avoided by having a satisfactory spectral signature (Gao and Liu, 2010). The extracted features are finally used for supervised classification of kanyakumari district to classify the pixels to the correct class without any confusion. With the use of global features six classes are determined from the Landsat satellite imagery of 2015 using five different classification algorithms, each algorithm showing different interest in particular class. The total pixels of each class is shown in Table 1.

Table 1: Total Pixel Count of Each Class

\begin{tabular}{|c|c|c|}
\hline \multicolumn{2}{|c|}{ Area of Region of Interest } & \\
\hline Class & No of pixels & \\
\hline Hilly Area: & & 12,281 Pixels \\
\hline Forest: & & 161,589 Pixels \\
\hline Agriculture: & & 8,749 Pixels \\
\hline Builtup: & & 6,407 Pixels \\
\hline Waterbodies: & & 6,717 Pixels \\
\hline
\end{tabular}




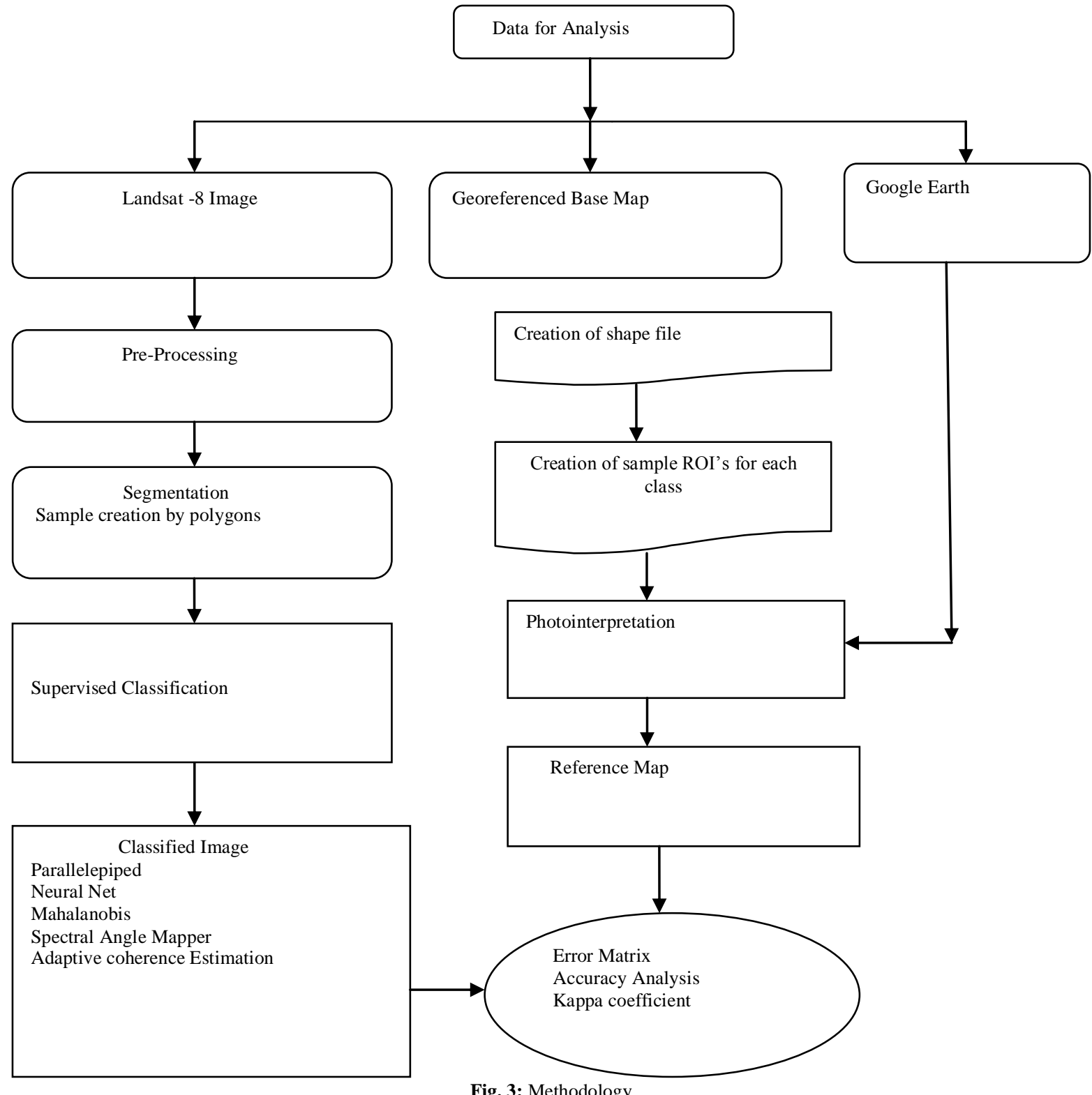

Fig. 3: Methodology

\section{Classification Methods}

The automatic classification algorithms that are considered here such as parallelepiped, Mahalanobis, Neural Net, Adaptive Coherence and Spectral Angle Mapper are because of its fast performance and acceptable accuracy. The classification is done based on the resolution of the pixels as this is one of the main features that gives better accuracy. For this to be implemented successfully the system has to be trained to group the pixels that belong to the same category by giving some input from an analyst before the algorithm is run. This procedure is referred to as the supervised classification. With this approach, when the image is fed to the system, it groups the pixels according to the category and classifies.

Five supervised classification methods, parallelepiped, Mahalanobis distance, Neural net, Adaptive Coherence and Sectral Angle Mapper are analysed here for selecting an optimum classifier to identify the land use land cover of kanyakumari district.

\section{Parallelepiped Classification}

The parallelepiped classifier which is one of the hard supervised classification algorithm is chosen here for the classification of multispectral images. Hard classification algorithms groups and classifies the pixels which exactly belong to one category. It will never classify the pixels where two classes are mixed. In this classification the threshold of each spectral signature will be defined and this determines whether a given pixel falls within the particular class or different. Depending on the decision rule the Supervised parallelepiped classification was carried out by comparing each pixel with the training samples. If the value of the pixel falls above the given threshold, it is assigned to that particular class and if it falls in the range of more than one class it is assigned to the most likely matched class. Pixels which do not fall in the range of any of the class are considered as unclassified.. (Mei Xiang 2005) worked out an unsupervised multispectral parallelepiped classifier with the help of genetic algorithms. In this algorithm, a new approach can also be used to estimate the initial range.

$s=\frac{\sqrt{\sum(r-x) 2}}{n}$

$x=\frac{s r}{n}$

S- Standard deviation

$\mathrm{X}$-mean(average of the pixels)

r- Value of each pixel 
n- no of pixels

\section{Mahalanobis Distance Classification}

Mahalanobis Distance Classification is used to classify the remote sensing satellite data as various classes like vegetation, hilly area, waterbodies, bare land and also other possibilities on the basis of the distance between the point $\mathrm{p}$ and the distribution $\mathrm{D}$. The Mahalanobis distance classification was proposed in 1930 by Mahalanobis (Mahalanobis, 1930). It has played a very important role in remote sensing satellite data analysis with multiple measurements such as classes $\mathrm{C} 1, \mathrm{C} 2 \ldots \mathrm{Cn}$ and then summarizing the difference between the different classes.

The aim of this classification is to form clusters of pixels which are similar to each other. when two classes overlap, it gives an error. This error can be measured in terms of $\mathrm{D}^{2}$, where $\mathrm{D}^{2}$ gives the variation in sampling.

$D^{2}=(x-m)^{T} C^{-1}(x-m)$

Where

$\mathrm{D}^{2}=$ Mahalanonis distance

$\mathrm{X}=$ Vector of data

$\mathrm{m}=$ Vector mean values of independent variables

$\mathrm{C}^{-1}=$ Inverse Covariance matrix of independent variables

$\mathrm{T}=$ Matrix transpose

\section{Neural Net Classification}

The ANN has a set of interconnected nodes where the output of each node is connected through weights to the next node. The important parts to be considered in ANN are the nodes, the geometry of their interconnections and the point where the connection originates and terminates are essential for an ANN. The performance of the ANN, is improved with the help of the activation functions such as identity functions, step functions and sigmoid functions which is applied over the net input to calculate the output.

Artificial neural network is an empiricial modeling tool which has the ability to identify the complex relationship of a network from input-output data without the requirement of any detailed information about the system (Muhammad et al,2006). ANN learns the ability of the network from the previously recorded data, input data, controlled and uncontrolled variables (Minns, and Hall,1996). ANNs has the ability to solve large-scale complex problems such as pattern recognition.

$y_{k}(x)=\sum_{i=1}^{d} W_{k i} X_{i}+W_{k 0}$

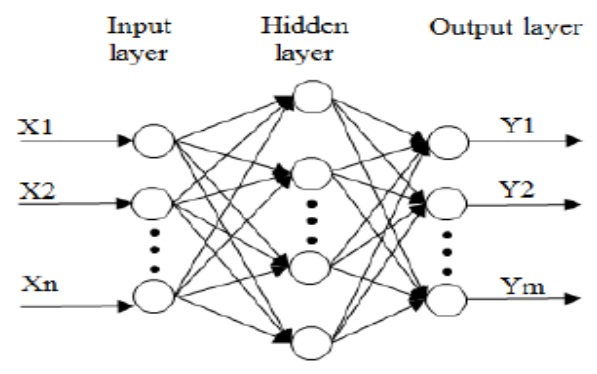

Fig. 4: Neural network

\section{Adaptive Coherence Estimator}

For nonhomogeneous environments, the Adaptive Coherence Estimate detector satisfies the constant false alarm rate (CFAR) property. A particular pixel level is fixed and if the pixel level crosses the threshold it is considered that it belongs to that particular class. The threshold can be raised and lowered to maintain a constant probability of false alarm. A fixed threshold level was fixed, as the background against which the targets are to be detected is constant with time and space. Unwanted clutter and interference cause changes in disturbance level. The standard binary hypothesis test for the detection problem is formulated as.

$H_{0}:\left\{\begin{array}{r}k=n \\ k_{l}=n_{l}\end{array}, l=1, \ldots \ldots L\right.$

$H_{1}:\left\{\begin{array}{c}k=\alpha v+n \\ k_{l}=n_{l,}\end{array}, \mathrm{l}=1, \ldots \ldots \mathrm{L}\right.$

Where $n$ and $n_{1}$ are independent of each other.

\section{Spectral Angle Mapper (SAM)}

The spectral angle mapper calculates the spectral similarity between two spectra by treating them as vectors (Kruse et al., 1993; Boardman, 1992). The angle between each pixel and sample spectra in $n$-dimension space is calculated. Smaller angles represent closer matches to the reference spectrum (Kurse et al., 1993). SAM classification considers reflectance data than radiance data. Classification can also be done by enforcing thresholds of maximum angles or by classifying each pixel to the most similar endmember.

Spectral angle mapper can be given by the formula

$\propto=\cos ^{-1} \frac{\sum X Y}{\sqrt{\sum(X)^{2} \sum(Y)^{2}}}$

which is represented in terms of radians.

$\alpha=$ Angle formed between reference spectrum and image spectrum

$\mathrm{X}=$ Image spectrum

$\mathrm{Y}=$ Reference spectrum

$\cos \propto=\frac{\sum X Y}{\sqrt{\sum(X)^{2}} \sum(Y}$

$\cos \propto=\frac{\sum X Y}{\sqrt{\sum(X)^{2} \sum(Y)^{2}}}$

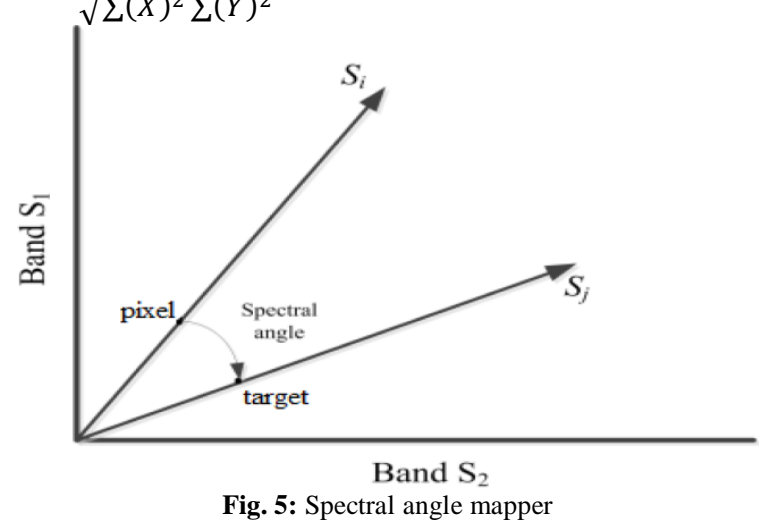

Post-Processing

Post classification is a process to remove the 'salt and pepper' appearance of the image created by the freckles and noise of the misclassified isolated pixels or group of pixels after classification and to improve the quality of the output.This process is carried out in three steps, filtering,smoothing and generalizing. The classification accuracy is calculated using confusion matrix which gives the result by comparing the classified output with the reference image, with gound truth ROI.

Kappa coefficient is calculated when the same data is used for more than one analysis. This finds the agreement between the users and adjust the values for the amount of agreement. Kappa coefficient first calculates the value in the main diagonal and then adjusts the values according to the agreement. kappa coefficient $(\kappa)$ is given by:

$\begin{array}{cccc} & & \text { Raster\#2 } & \\ & 1 & 2 & \text { Total } \\ 1 & \mathrm{P}_{11} & \mathrm{P}_{12} & \mathrm{P}_{1}\end{array}$




$\begin{array}{ccccc}\text { Raster\#1 } & 2 & \mathrm{P}_{21} & \mathrm{P}_{22} & \mathrm{P}_{2} \\ & \text { Total } & \mathrm{P}_{11} & \mathrm{P}_{22} & 1\end{array}$

$\mathrm{P}_{\mathrm{o}}$ - Observed level of Agreement

$\mathrm{P}_{\mathrm{e}}$ - Expected level of agreement

$\mathrm{P}_{\mathrm{o}}=\mathrm{p}_{11}+\mathrm{p}_{22}$

$\mathrm{P}_{\mathrm{e}}=\mathrm{P}_{1} \mathrm{P}_{1}+\mathrm{P}_{2} \mathrm{P}_{2}$

$K=\frac{P_{o}-P_{e}}{1-P_{e}}$

Kappa coefficient is always less than or equal to 1 . Value of 1 indicates perfect agreement.

\section{Experimental Results and Discussions}

The aim of this study is to produce a land use/land cover map of kanyakumari district that had experienced a bad impact of psunami , an increase of urban population and builtup in the recent decades and the deterioration in water bodies.

When analyzed all five results with the google earth using photo interpretation, and the hands on experience in the image analysis it is concluded that Spectral Angle Mapper has given the highest accuracy compared to parallelepiped, Mahalanobis, Neural Net and Adaptive coherence.Thus the results have given the overall accuracies of $26 \%$ for parallelepiped, $72.78 \%$ for neur al net, $73 \%$ for Mahalanobis distance, $96.32 \%$ for Adaptive Coherence Estimation and $96.62 \%$ for Spectral Angle Mapper. The overall kappa co-efficient values are $-0.001,0.34,0.34,0.49$ and 0.54 respectively. Gupta and srivasta, 2010). The user's and producer's accuracies measurements are related to commission and omission errors(congalton,19191; Gupta and Srivasta, 2010).

\section{Classification Accuracy Analysis}

The classification procedure carried out in this paper is practically the same for all the algorithms. The only thing that differs is the parameter that sets the sensitivity of the procedure. The five best algorithms chosen for the analysis of land use land cover of kanyakumari district were optimised to get the best land use land cover maps as shown in fig. and each one was compared with the reference data to acquire the accuracy of the classification algorithms.

The procedures of supervised classification start from creating a training set. In ENVI regions of interest (ROIs) are created using polygons. Each class has its own set of ROIs. This ROI's are confirmed by checking the quality of regions of interest with the help of print preview.

In this paper all five classifications were carried out with the help of the software ENVI 5.1. For the parallelepiped classification to be performed the software requires two parameters for each of the classes. These are the average brightness value and standard deviation from the mean. Both parameters that are necessary for classification are calculated by the software from training samples created by the user. The parallelepiped classification has given an overall accuracy of $26 \%$ with a kappa coefficient of -0.001 which is a rare case. When compared to other classifiers, considered in this paper the parallelepiped has given a very less accuracy and kappa coefficient. In the mean time the user accuracy and producer accuracy as shown in Table.5 is zero for Builtup, Agriculture, Hilly area and 'nan' which says it is not a number for Bareland.It has also given $36.5 \%$ of user accuracy for waterbodies and $100 \%$ for forest. At the same time it has given $0.1 \%$ of producer accuracy for waterbodies and 34.3 for forest.

Neural net classifier which has given an accuracy of $72.78 \%$ with a kappa coefficient of 0.34 is a classifier with the structure of the brain. Neural net classifier process one record at a time and compare this with the known value of the record. The error value from this is fed back to the network for correction. The same process is continued till the end of the network and this is used to assign the weight for each hidden node in the network. After all trial and error procedures the user accuracy acquired for Builtup is $79.6 \%$, waterbodies $89 \%$, Agriculture $54.8 \%$, Hilly area 0.1669 , forest $100 \%$ and Bare land $30.1 \%$. The producer accuracy which is given as $79.4 \%$ for Builtup, $82.8 \%$ for waterbodies $13.14 \%$ for Agriculture, $0.05 \%$ for Hilly area, 0.05 for forest and 10.416 for Bare land.

Mahalanobis distance classification is done in terms of standard deviation. It calculates the the distance between the point $\mathrm{P}$ and the distribution $\mathrm{D}$ interms of standard deviation. If $\mathrm{P}$ is at the mean of $\mathrm{D}$ then the distance is zero. It is unitless and scale-invariant. The mahalanobis distance which has given almost the same accuracy of neural net with $73 \%$ of overall accuracy and kappa coecfficient of 0.34 has achieved almost the same user accuracy for builtup with $79.8 \%, 88.79$ for waterbodies, $59.04 \%$ for Agriculture, $0.09 \%$ for Hilly area, $100 \%$ for forest and $100 \%$ for Bareland which is the unique output when compared with other classifiers. The producer accuracy of neural net and mahalanobis almost lies in the same range as shown in Table 5.

The Adaptive Coherence and the Spectral Angle Mapper have an accuracy of $96.32 \%$ and $96.63 \%$ with a kappa coefficient of 0.49 and 0.54 . The adaptive coherence which was considered to be the best is overcomed by Spectral angle mapper proving it as the best suitable algorithm for the classification of landsat image. The adaptive coherence has the user and producer accuracy for builtup as $89.6 \%$ and $99.9 \%$ and with $99.9 \%$ as both user and producer accuracy for waterbodies, $5.7 \%$ and $2.07 \%$ for Agriculture, $25.5 \%$ and $3.8 \%$ for hilly area and $0.155 \%$ and $0.51 \%$ for Forest area and Zero for bareland.

The spectral angle mapper which has overcome the Adaptive Coherence in accuracy and kappa coefficient has the user and producer accuracy for builtup as $99.9 \%$. It has acquired a Zero value for waterbodies, Agriculture and hilly area. It is also bagged with a user accuracy of $56.9 \%$ and a producer accuracy of $84 \%$ for forest. The user accuracy for bare land is 'nan' and zero for producer accuracy for bareland. The detailed picture is given in Table 5.

Table 2: Class Vs Area

\begin{tabular}{|c|c|c|c|c|c|}
\hline \multicolumn{6}{|c|}{ Area } \\
\hline $\begin{array}{l}\text { Classifica } \\
\text { tion }\end{array}$ & $\begin{array}{l}\text { Neural } \\
\text { Net }\end{array}$ & $\begin{array}{l}\text { Mehalanob } \\
\text { asis }\end{array}$ & $\begin{array}{l}\text { Parallelopi } \\
\text { ped }\end{array}$ & $\begin{array}{l}\text { Adaptiv } \\
\mathrm{e} \\
\text { Coheren } \\
\text { ce }\end{array}$ & $\begin{array}{l}\text { Spectral } \\
\text { Angle } \\
\text { Mapper }\end{array}$ \\
\hline \multicolumn{6}{|l|}{ Class } \\
\hline Builtup & $\begin{array}{l}515205 \\
000\end{array}$ & 176887800 & $\begin{array}{l}12603951 \\
0\end{array}$ & $\begin{array}{l}399075 \\
00\end{array}$ & $\begin{array}{l}416007 \\
00\end{array}$ \\
\hline $\begin{array}{l}\text { Waterbod } \\
\text { ies }\end{array}$ & $\begin{array}{l}260811 \\
00\end{array}$ & 52766100 & 26913600 & $\begin{array}{l}537440 \\
62\end{array}$ & $\begin{array}{l}602577 \\
00\end{array}$ \\
\hline $\begin{array}{l}\text { Agricultur } \\
\mathrm{e}\end{array}$ & $\begin{array}{l}312117 \\
300\end{array}$ & 431566200 & 86490000 & $\begin{array}{l}600170 \\
937\end{array}$ & $\begin{array}{l}676562 \\
400\end{array}$ \\
\hline $\begin{array}{l}\text { Hilly } \\
\text { Area }\end{array}$ & $\begin{array}{l}674143 \\
200\end{array}$ & 800653500 & $\begin{array}{l}22018770 \\
0\end{array}$ & $\begin{array}{l}519534 \\
531\end{array}$ & $\begin{array}{l}452353 \\
500\end{array}$ \\
\hline Forest & $\begin{array}{l}961794 \\
00\end{array}$ & 186415200 & 18728100 & $\begin{array}{l}365915 \\
937\end{array}$ & $\begin{array}{l}314894 \\
700\end{array}$ \\
\hline Bare land & $\begin{array}{l}320058 \\
00\end{array}$ & 7443000 & 6089400 & $\begin{array}{l}152815 \\
62\end{array}$ & $\begin{array}{l}235368 \\
00\end{array}$ \\
\hline
\end{tabular}

Table 3: Class Vs Pixel Sum

\begin{tabular}{|l|l|l|l|l|l|}
\hline \multicolumn{7}{|c|}{ Pixel Sum } \\
\hline $\begin{array}{l}\text { Classificati } \\
\text { on }\end{array}$ & $\begin{array}{l}\text { Neura } \\
1 \text { Net } \\
\text { bis }\end{array}$ & $\begin{array}{l}\text { Mehalano } \\
\text { ed }\end{array}$ & $\begin{array}{l}\text { Parallelopip } \\
\text { Coheren } \\
\text { ce }\end{array}$ & $\begin{array}{l}\text { Spectr } \\
\text { al } \\
\text { Angle } \\
\text { Mappe } \\
\text { r }\end{array}$ \\
\hline Class & & & & 255408 & 46223 \\
\hline Builtup & $\begin{array}{l}57245 \\
0\end{array}$ & 196542 & 1400439 & 343962 & 66954 \\
\hline $\begin{array}{l}\text { Waterbodie } \\
\text { s }\end{array}$ & 28979 & 58629 & 29904 & 3841094 & $\begin{array}{l}75173 \\
6\end{array}$ \\
\hline Agriculture & 34679 & 479518 & 96100 & 3325021 & 50261 \\
\hline Hilly Area & 74904 & 889615 & 244653 & & \\
\hline
\end{tabular}




\begin{tabular}{|l|l|l|l|l|l|}
\hline & 8 & & & & 5 \\
\hline Forest & $\begin{array}{l}10686 \\
6\end{array}$ & 207128 & 20809 & 2341862 & $\begin{array}{l}34988 \\
3\end{array}$ \\
\hline Bare land & 35562 & 8270 & 6766 & 97802 & 26152 \\
\hline
\end{tabular}

Table 4: Overall Accuracy and Kappa Cooefficient

\begin{tabular}{|c|c|c|c|c|c|}
\hline $\begin{array}{l}\text { Classificati } \\
\text { on }\end{array}$ & $\begin{array}{l}\text { Parallelepip } \\
\text { ed }\end{array}$ & $\begin{array}{l}\text { Neur } \\
\text { al } \\
\text { Net }\end{array}$ & $\begin{array}{l}\text { Mehalanob } \\
\text { is Distance }\end{array}$ & $\begin{array}{l}\text { Adaptive } \\
\text { Coheren } \\
\text { ce }\end{array}$ & $\begin{array}{l}\text { Spectr } \\
\text { al } \\
\text { Angle } \\
\text { Mappe } \\
\text { r }\end{array}$ \\
\hline $\begin{array}{l}\text { Overall } \\
\text { Accuracy }\end{array}$ & $26 \%$ & 72.78 & $73 \%$ & $96.32 \%$ & $\begin{array}{l}96.62 \\
\%\end{array}$ \\
\hline $\begin{array}{l}\text { Kappa- } \\
\text { Co.efficient }\end{array}$ & -0.001 & 0.34 & 0.34 & 0.49 & 0.54 \\
\hline
\end{tabular}

Overall Accuracy

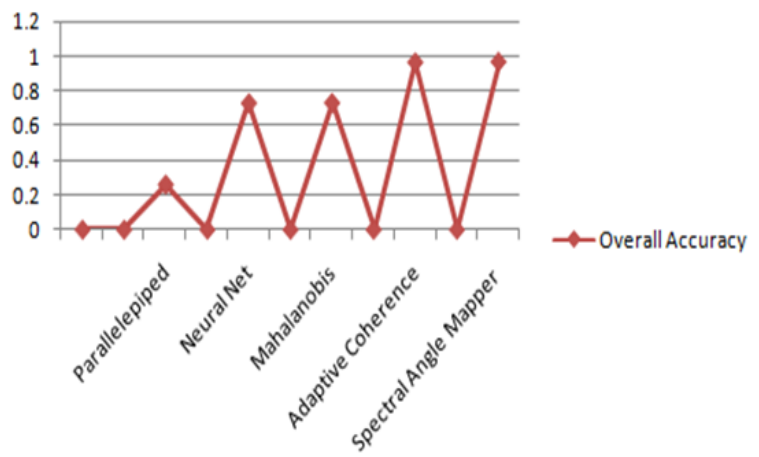

Kappa Coefficient

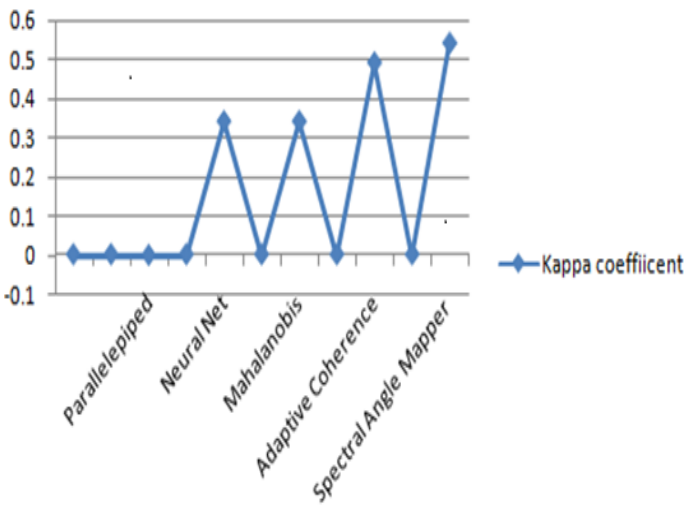

Fig. 7: Accuracy analysis(Kappa coefficient)

Fig. 6: Accuracy analysis

Table 5: Kappa Statistics and Overall Classification Accuracy, User Accuracy and Producer Accuracy of Classifiers Used in this Study

\begin{tabular}{|c|c|c|c|c|c|c|c|c|}
\hline \multirow{2}{*}{$\begin{array}{l}\text { classification } \\
\text { Technique }\end{array}$} & \multirow{2}{*}{$\begin{array}{l}\text { Overall } \\
\text { Accuracy }\end{array}$} & \multirow{2}{*}{$\begin{array}{l}\text { Kappa } \\
\text { coeffiicent }\end{array}$} & \multirow[b]{2}{*}{ Builtup } & \multicolumn{3}{|c|}{ User Accuracy } & \multirow[b]{2}{*}{ Forest } & \multirow[b]{2}{*}{ Bareland } \\
\hline & & & & Waterbodies & Agriculture & Hilly Area & & \\
\hline Parallelepiped & $26 \%$ & -0.001 & 0 & 36.5 & 0 & 0 & 100 & nan \\
\hline Neural Net & $72.78 \%$ & 0.34 & 79.6 & 89 & 54.8 & 0.1669 & 100 & 30.1 \\
\hline Mahalanobis & $73 \%$ & 0.34 & 79.8 & 88.79 & 59.04 & 0.09 & 100 & 100 \\
\hline Adaptive Coherence & $96.32 \%$ & 0.49 & 89.6 & 99.9 & 5.7 & 25.5 & 0.155 & 0 \\
\hline \multirow[t]{3}{*}{ Spectral Angle Mapper } & $96.63 \%$ & 0.54 & 99.9 & 0 & 0 & 0 & 56.9 & Nan \\
\hline & & \multicolumn{3}{|c|}{ Producer Accuracy } & & & & \\
\hline & Builtup & Waterbodies & Agriculture & Hilly Area & Forest & Bareland & & \\
\hline Parallelepiped & 0 & 0.1 & 0 & 0 & 34.3 & 0 & & \\
\hline Neural Net & 79.4 & 82.8 & 13.14 & 0.05 & 10.416 & 11.15 & & \\
\hline Mahalanobis & 78.6 & 83.99 & 15.35 & 0.05 & 8.33 & 0.39 & & \\
\hline Adaptive Coherence & 89.2 & 99.9 & 2.07 & 3.8 & 0.51 & 0 & & \\
\hline Spectral Angle Mapper & 99.9 & 0 & 0 & 0 & 84 & 0 & & \\
\hline
\end{tabular}

\section{Experimental Analysis (Post Processing)}

The post processing analysis for the five classified images are done by using Error matrix analysis. The overall accuracy has shown that the Spectral Angle Mapper has acquired the highest accuracy than the other four classiifers. For the builtup class all the classifiers has almost the same percentage for user's and producer's accuracy in the range of $70-100 \%$ with a maximum of $100 \%$ for spectral angle mapper and the least Zero for parallelepiped. The classification of the waterbodies by the Neural net and Mahalanobis showed an user's accuracy and producer's accuracy in the range of $80-90 \%$ and the Adaptive Coherence had given an accuracy of $99.9 \%$ in both which is higher han the other two and $36.5 \%$ for parallelepiped and Zero for Spectral angle mapper. Neural net and mahalanobis which is almost in the same range with user's and producer's accuracy of nearly 54-60\% and 13-15\% but Adaptive Coherence with 5.7\% user's accuracy for the class agriculture and $2.07 \%$ producer's accuracy and with a value zero for both parallelepiped and Spectral Angle mapper respectively when compared to other three. In the case of hilly area, both the User's and producer's accuracy of Neural Net and Mahalanobis are in the range of 0.1 and $0.05 \%$ and less when compared to Adaptive Coherence which has 25\% user's accuracy and $3.8 \%$ producer's accuracy and the parallelepiped and Spectral angle with a zero value. Other class considered herein is forest which has an user's accuracy of $100 \%$ for both Neural Net and Mahalanobis and $0.15 \%$ for Adaptive Coherence and with a $100 \%$ user accuracy $34.3 \%$ producer accuracy for parallelepiped. The last class bareland have an user's accuracy of $30 \%$ and $100 \%$ for Neural Net and Mahalanobis and 0.00 for Adaptive Coherence 'nan' for Spectral angle mapper and producer accuracy of $11.15 \%$ and $0.39 \%$ and $0.0 \%$ for both adaptive and Spectral Angle mapper which is a relatively poor accuracy. [43]

\section{Analysed Output}

The classification maps formed from the execution of the parallelepiped, Mahalanobis, Neural net, Adaptive Coherence and Spectral Angle Mapper are shown in fig 8 . (Senthil Lekha 2015,2018) The performance of few supervised classification algorithms with the use of EnvI 5.1 was analysed and proved. The land cover map, result of five different algorithms are given in fig 6,7. In this analysis the Landsat-8 satellite image for the year 2015 has been classified for six classes such as (1) Builtup, (2) waterbodies, (3) Agriculture, (4) Hilly area, (5) Forest, and (6) 
Bare Land. From the output the Spectral Angle Mapper is found to be the best from the analyzed output. The results indicate that, in all five algorithms the Spectral Angle Mapper has shown the best performance with an accuracy of $96.63 \%$ and a kappa coefficient of 0.54 is considered as the best suited algorithm for the classification of Landsat-8 images. The class $\mathrm{V}_{\mathrm{s}}$ area and the class $\mathrm{V}_{\mathrm{s}}$ Pixel sum are shown in Table 2 and 3.[42]

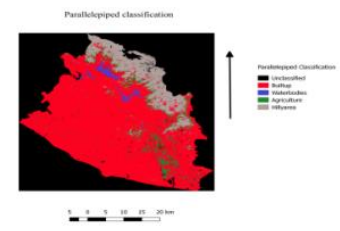

(a)Parallelepiped classification

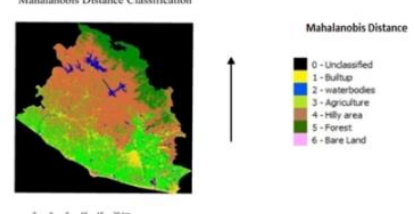

(b) Mahalanobis distance classification

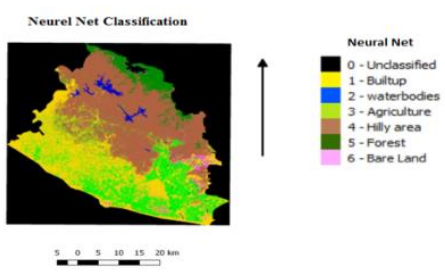

(c) Neural net classification

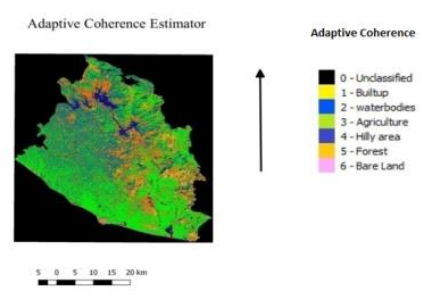

(d) Adaptive coherence estimation

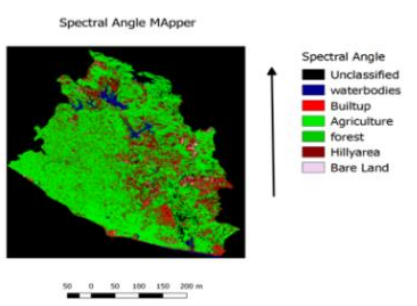

(e) Spectral angle mapper

Fig. 8: Experimental Results, (a) Parallelepiped Classification, (b) Mahalanobis Distance Classification, (c) Neural Net Classification, (d) Adaptive Coherence Estimation and (e) Spectral Angle Mapper

\section{Conclusion}

The land use land cover classification of landsat image is a process of converting the pixels in a satellite image into different land cover classes. There are $\mathrm{n}$ number of classification algorithms that can be used to group image pixels in to land cover classes, unfortunately the best algorithm for the classification of each class is not identified. The selection of a suitable algorithm depends on many factors and the familiarity and experience with different methods. The technique chosen in our analysis is the supervised automated classification technique in which the algorithm is used to assign individual pixels or group of pixels to one of the valid classes, which helps in saving the time and immediate update of the map. In the automated approach the algorithm is applied systematically throughout the entire image relatively quickly. The best algorithm is chosen by finding the Overall Classification Accuracy, Kappa Co-efficient, User Accuracy and Producer Accuracy. The performance is clearly shown in Table 1, 2, 3 and 4 and 5 respectively.

Error matrix analysis was performed by comparing each classified output map to a reference map of information source. The main purpose of accuracy and error matrix analysis is to have quantitative and qualitative comparisons of different algorithms and to choose the best among them. In this analysis the results are examined to direct the "most suitable" and "most applicable" algorithm for the landsat image.

The performance of each algorithm was also evaluated by validating the kappa coefficient, overall accuracy, user accuracy and producer accuracy. The classified images, parallelepiped, Adaptive Coherence Estimator, Neural net classification, Mahalanobis Distance Classification and Spectral Angle Mapper have proved that each algorithm is suitable for a specific LULC. Spectral Angle Mapper which has an overall accuracy of $96.63 \%$ and kappa coefficient 0.54 has overcome the Adaptive Coherence which has gained an overall accuracy of 96.3 and 0.43 kappa coefficient is considered to be the best among all five classifiers and proved that it is more applicable for satellite image classification compared with Mahalanobis Distance which has an overall accuracy of $72.78 \%$ and kappa coefficient of 0.34 . Neural Net has an overall accuracy of $73 \%$ and kappa coefficient of 0.34 which is the same as Mahalanobis Distance classification and parallelepiped which has an overall accuracy of 26\% and kappa coefficient of -0.001 which happens in a rare case.

Study shows that Spectral Angle Mapper outperformed the Adaptive Coherence algorithm in the overall accuracy and kappa co-efficient proving it as the best algorithm for the analysis of landsat image. But it can also be said that each algorithm has its best analyzing power for the particular class of LCLU.

Future research can be focussed on the analysis of the landsat image using different bands, as each band plays a different role in different land cover class which in turn helps to increase the overall accuracy and kappa coefficient by reproducing a perfect map.

\section{References}

[1] Agarwal C, Green GM, Grove JM, Evans TP \& Schweik CM, "A Review and Assessment of Land-Use Change Models Dynamics of Space, Time, and Human Choice", Gen. Tech. Rep. NE-297. Newton Square, PA: US Department of Agriculture, Forest Service, Northeastern Research Station, (2001).

[2] Butt A, Shabbir R, Ahmad SS \& Aziz N, "Land use change mapping and analysis using Remote Sensing and GIS: A case study of Simly watershed, Islamabad, Pakistan", The Egyptian Journal of Remote Sensing and Space Science, Vol.18, No.2,(2015), pp.251259.

[3] Aspinall R, "Modelling land use change with generalized linear models-a multi-model analysis of change between 1860 and 2000 in Gallatin Valley, Montana", Journal of environmental management, Vol.72, No.1-2,(2004), pp.91-103.

[4] Fröhlich B, Bach E, Walde I, Hese S, Schmullius C \& Denzler J, "Land cover classification of satellite images using contextual information", ISPRS Annals of the Photogrammetry, Remote Sensing and Spatial Information Sciences, (2013).

[5] Blaschke T, Burnett C \& Pekkarinen A, "Image segmentation methods forobject-based analysis and classification", Remote sensing image analysis:Including the spatial domain, (2004), pp. 211-236.

[6] Boardman, "SIPS User's Guide Spectral Image Processing System, Version 1.2", Center for the Study of Earth from Space, Boulder, (1992). 
[7] Ndehedehe C, Ekpa A, Simeon O \& Nse O, "Understanding the neural network technique for classification of remote sensing data sets", NY Sci J, Vol.6, (2013), pp.26-33.

[8] Dickinson RE, "Land processes in climate models", Remote Sensing of Environment, Vol.51, (1995), pp.27-38.

[9] Foody G, "Remote sensing of tropical forest environments: towards the monitoring of environmental resources for sustainable development", International Journal of Remote Sensing, Vol.24, (2003), pp.4035-4046.

[10] Geist HJ, "The Land-use And Cover-Change (LUCC) Project", Land Use, Land Cover and Soil Sciences-Volume I: Land Cover, Land Use and the Global Change, (2009).

[11] Gupta M \& Srivastava PK, "Integrating GIS and remote sensing for identification of groundwater potential zones in the hilly terrain of Pavagarh, Gujarat, India", Water International, Vol.35, (2010), pp.233-245.

[12] Hegazy IR \& Kaloop MR, "Monitoring urban growth and land use change detection with GIS and remote sensing techniques in Daqahlia governorate Egypt", International Journal of Sustainable Built Environment, Vol.4, No.1,(2015), pp.117-124.

[13] Iqbal MF \& Khan IA, "Spatiotemporal land use land cover change analysis and erosion risk mapping of Azad Jammu and Kashmir, Pakistan", The Egyptian Journal of Remote Sensing and Space Science, Vol.17, No.2,(2014), pp.209-229.

[14] Jan 5, 2017 LULCC can play a vital role in natural resources management (Iqbal and Khan, 2014;Kantakumar and Neelamsetti, 2015; Lin et al., 2015).

[15] Merchant JW \& Narumalani S, Integrating remote sensing and geographic information systems, SAGE Publications Ltd: London, UK, (2009).

[16] Kaliraj S, Chandrasekar N, Ramachandran KK, Srinivas Y \& Saravanan S, "Coastal landuse and land cover change and transformations of Kanyakumari coast, India using remote sensing and GIS", The Egyptian Journal of Remote Sensing and Space Science, Vol.20, No.2,(2017), pp.169-185.

[17] B Kassimbekova, G Tulekova, V Korvyakov (2018). Problems of development of aesthetic culture at teenagers by means of the Kazakh decorative and applied arts. Opción, Año 33. 170-186

[18]

[19] Kantakumar LN \& Neelamsetti P "Multi-temporal land use classification using hybrid approach", Egypt. J. Remote Sens. Space Sci., Vol.18, (2015), pp.289-295.

[20] Kruse FA, Lefkoff AB, Boardman JW, Heiedbrecht KB, Shapiro AT, Barloon PJ \& Goetz AFH, "The Spectral Image Processing System (SIPS)-Interactive Visualization and Analysis of Imaging Spectrometer Data", REMOTE SENS. ENVIRON.,Vol.44, (1993), pp.145-163.

[21] (PDF) Spectral Correlation Mapper (SCM): An.... Available from: https://www.researchgate.net/publication/267721109_Spectral_Cor relation_Mapper_SCM_An_Improvement_on_the_Spectral_Angle _Mapper_SAM [accessed Jul 13 2018].

[22] Lambin EF, "Modelling and monitoring land-cover change processes intropical regions", Progress in Physical Geography, (1997).

[23] Xiang M, Hung CC, Pham M, Kuo BC \& Coleman T, "A parallelepiped multispectral image classifier using genetic algorithms", Proceedings. IEEE International Geoscience and Remote Sensing Symposium, (2005).

[24] Mukherjee S, Sashtri S, Gupta M, Pant MK, Singh C, Singh SK, Srivastava PK \& Sharma KK, "Integrated water resource management using remote sensing and geophysical techniques: Aravali quartzite, Delhi, India", Journal of Environmental Hydrology, (2007).

[25] Rahman, MT, "Detection of land use/land cover changes and urban sprawl in Al-Khobar, Saudi Arabia: An analysis of multi-temporal remote sensing data" ISPRS International Journal of GeoInformation, Vol.5, No.2, (2016).

[26] Kayet N \& Pathak K, "Remote sensing and GIS based land use/land cover change detection mapping in Saranda Forest, Jharkhand, India", Int Res J Earth Sci, Vol.3, No.10,(2015), pp.1-6.

[27] Nemani R \& Running S, "Land cover characterization using multitemporal red, near-IR, and thermal-IR data from NOAA/AVHRR”, Ecological applications, Vol.7(1), (1997), pp.79-90.

[28] Mahmon NA, Ya'Acob N \& Yusof AL, "Differences of image classification techniques for land use and land cover classification. IEEE 11th International Colloquium on Signal Processing \& Its Applications (CSPA), (2015), pp.90-94.
[29] Srivastava PK, Han D, Rico-Ramirez MA, Bray M \& Islam T, "Selection of classification techniques for land use/land cover change investigation", Elsiever,Advances in Space Research, Vol.50, (2012), pp.1250-1265.

[30] Patel D, Dholakia M, Naresh N \& Srivastava P, "Water harvesting structure positioning by using geo-visualization concept and prioritization of mini-watersheds through morphometric analysis in the lower Tapi Basin", Journal of the Indian Society of Remote Sensing, Vol.40, (2012), pp.299-312.

[31] Lv Q, Dou Y, Niu X, Xu J, Xu J \& Xia F, "Urban land use and land cover classification using remotely sensed SAR data through deep belief networks", Journal of Sensors, (2015).

[32] Rawat JS \& Kumar M, "Monitoring land use/cover change using remote sensing and GIS techniques: A case study of Hawalbagh block, district Almora, Uttarakhand, India", The Egyptian Journal of Remote Sensing and Space Science, Vol.18, No.1,(2015), pp.7784.

[33] Richards IA \& Xi J, Remote Sensing Digital Image Analysis-An Introduction, 3rd ed. Springer; Berlin, Germany, (1996).

[34] Richards JA \& Richards JA, Remote sensing digital image analysis, Berlin et al.: Springer, (1999).

[35] Senthil lekha SL \& Kumar SS, "Land cover change analysis of kanyakumari district using sensor images in GIS environment", International Journal of Applied Engineering Research, Vol.10, No.70,(2015), pp.279-287.

[36] Senthil lekha SL \& Kumar SS, "Classification and Mapping of Land Use Land Cover change in Kanyakumari district with Remote Sensing and GIS techniques", International Journal of Applied Engineering Research, Vol.13, No.1, (2018), pp.158-166.

[37] Rwanga SS \& Ndambuki JM, "Accuracy assessment of land use/land cover classification using remote sensing and GIS", International Journal of Geosciences, Vol.8, No.04,(2017), pp.611622.

[38] G Mussabekova, S Chakanova, A Boranbayeva, A Utebayeva, K Kazybaeva, K Alshynbaev (2018). Structural conceptual model of forming readiness for innovative activity of future teachers in general education school. Opción, Año 33. 217-240

[39] Veldkamp A \& Lambin EF, "Predicting land-use change", Agriculture, Ecosystems \& Environment, Vol.85, (2001), pp.1-6.

[40] Zeng YN, Wu GP, Zhan FB \& Zhang HH, "Modeling spatial land use pattern using autologistic regression", The International Archives of the Photogrammetry, Remote Sensing and Spatial Information Sciences, (2008).

[41] http://kanyakumari.nic.in/forest.htm

[42] http://www.cgwb.gov.in/District_Profile/TamilNadu/Kanyakumari. pdf

[43] http://shodhganga.inflibnet.ac.in/bitstream/10603/43207/9/09_chapt er\%201.pdf 